\title{
Commentary
}

\section{Understanding ethnicity in contemporary Australia using the census}

Liz Allen The Australian National University

Email: Liz.Allen@anu.edu.au. Address: Centre for Social Research and Methods, The Australian National University, Acton, ACT 2601, Australia.

Paper received 22 February 2021; accepted 6 May 2021; published 31 May 2021

\section{Introduction}

Australia is amongst the most ethnically and culturally diverse countries in the world. Despite this diversity, little is understood about how Australians identify with their ethnic heritage. Data collected on a national level via the five-yearly Census of Population and Housing do not adequately capture the complexity and richness of Australia's ethnic diversity. This inadequacy could be contributing to the lack of diversity and parity representation of the population in politics, business, and decision-making. In addition, there are benefits for individuals, business, and planning (among others) for a more comprehensive understanding of Australia's contemporary ethnic profile. How the national enumeration could better capture contemporary ethnic identity in Australia is considered here, with consideration of previous attempts at collection of such information in Australia and elsewhere alongside potential improvements for the 2026 Census.

\section{Ethnicity in the census}

\subsection{What is ethnic identity?}

"Ethnic identity is defined as a sense of belonging, based on ones' ancestry, cultural heritage, values, traditions, rituals, and often language and religion" (Green et al. 2015 p. 676). In practice, ethnic identity is a self-defined concept and can be a complex articulation of one's biological background and social experiences and practices, especially as it relates to migrant and mixed-race populations. Ethnicity is further complicated by the dynamic nature of individual articulation; self-reported identification can change over time, reflecting expanding experiences (United Nations 2017). In this way ethnicity, a socially constructed and individually interpreted embodiment of identity, differs from the outdated and problematic notions of race based on birthplace, heritage and/or even skin colour (Horn 1987).

Ethnicity and culture are often politically charged and highly sensitive concepts, especially for individuals and communities identified as visible minorities from, and by, the majority population. The sensitivity and loaded nature of these terms stem from their connection to race, which in Australia is 
related historically to eugenic practices of distinguishing people of white origins to others (Stevens et al. 2015) and their so-called racial purity. Despite the history of poor practices of collecting data concerning ethnicity in Australia, there has been growing expectations and attempts to better reflect contemporary ethnic identity in data collections to best capture the diversity of the nation (Allen 2020; Federation of Ethnic Communities' Council of Australia 2020).

\subsection{Collection of ethnicity indicators in the Australian census}

The census is vital in informing population estimates and trends, especially among hard to reach and minority populations (United Nations 2017). The value of capturing ethnic identity in the census (over collection in sample surveys) is wide ranging, but reflects the need for a whole-of-population enumeration that is also accessible to all. A whole-of-population enumeration enables data across all levels of geography to help identify populations of interest and in determining needs and services relating to such things as business and government. Sample survey data has the potential to overlook important aspects of the population on the topic of ethnicity, simply because the sampling frame lacks necessary insights from the census. This circular predicament of census and sampling frames is best resolved by bringing the census into line with contemporary Australian ethnic identity.

Horn $(1987,1993)$ and Rocha et al. (2018) identify shortcomings of the current approach to collecting ethnicity data in the census, but instead of recommending the census be updated (like Khoo 1991 does) they call for ethnicity information to be collected via sample surveys. The justification for avoiding updating the national census to include self-reported ethnic identity embodies a long-enduring fear Australia has had reckoning with its history. Horn (1993 p. 126) highlights the limitations of the current approach to understanding cultural diversity in census, but rather than making recommendations for improvements argues Australia may not be ready for a discussion about identity, saying such a move is likely to "evok[e] ancient ghosts". Khoo (1991) however argues that Australia needs to confront its history. The census and its related education campaign could be a way forward for the nation in reckoning with its past and looking to the future, through the lens of ethnicity.

The measurement of ethnic diversity can be methodologically and socially fraught at the best of times. But the environment in which the national statistical agency operates includes the legacies of brutal British colonisation, the discriminatory White Australia policy, and enduring xenophobia. The endeavour for meaningful data to best reflect the diversity of the Australian population must be understood in this complex and complicated context. The willingness of people (especially those from minority groups) to want to identify their ethnic identity should also be carefully weighed with the perceived national social benefits.

A range of questions designed to capture information relating to cultural background and diversity are asked as part of the Australian national population and housing census, these include: Indigenous status, citizenship status, country of birth, year of arrival for people born overseas, country of parent's birth, language other than English spoken at home, English proficiency, religion, and ancestry. These data items together are used to construct a picture of the characteristics of Australians based on cultural backgrounds (Khoo 1991). Most commonly however, country of birth and language are used as surrogate measures for, and ancestry as a direct measure of, ethnicity or ethnic identity (Horn 1987, 1993). 
The surrogate measures of country of birth and language, which serve as indicators of ethnicity, have been included in the Australian census since 1911 and 1986 (respectively) (ABS 2020; Horn 1987). These data, coupled with country of birth of parents are popularly used, although they are limited to two generations of reach in detail (Khoo 1991). For example, the ethnic identity of someone who identifies as Asian Australian would be missed from the full picture of Australian's diversity where the individual speaks English only and they and their parents were born in Australia. This would be an increasingly more common phenomenon, particularly as time passes from the early waves of migration, and as mixed partnering and multiracial births increase (Rocha et al. 2018).

While country of birth, language, and religion all provide vital details for provision of needs and services for example, these surrogate measures are inadequate for reflecting ethnic identity (Horn 1993). The inappropriateness of these surrogate measures increases with generations. Moreover, it is not just the understanding of diversity that benefits from more comprehensive and contemporary measures of ethnicity; business, local governments, individuals, and communities all stand to benefit.

The Australian census first included a direct question on ancestry in 1986 (ABS 2020), at a time when immigration from Asian countries overtook that from European nations for the first time in Australia's more recent history (Jupp 2001). Prior to this ancestry question, the Australian census included a question about race origins (Horn 1987, 1993). The inclusion of the ancestry question was the result of research into the best way to gauge ethnicity in Australia.

In 1982, the Australian Statistician appointed a committee to evaluate the collection of ethnicity data in the 1986 census. Headed by W.D. Borrie, the committee argued the need to move away from a racebased question to the inclusion of so-called surrogate measures of ethnicity (for example, the suite of questions presently in the census) and or a self-identified direct question on ancestry (ABS 1984). The committee oversaw a series of pilot tests covering a number of potential options, including both direct ancestry and ethnicity questions. The committee recommended "maximising the level and quality of responses to any ethnicity question, and of minimising any adverse reaction to such a question" (ABS 1984 p. 68). In doing so, the committee opted for simplicity over accuracy. The final 1986 question asked about each person's ancestry, and presented six example options: Greek, English, Indian, Armenian, Aboriginal, Chinese. A dissenting committee member warned this question was too crude an approach over a self-identified ethnicity question, and would not deliver the data required by the nation's "multicultural society" (ABS 1984 p. 71). Despite the best intentions, the self-reported ancestry variable in 1986 was unsuccessful in achieving its intended purpose, failing to adequately capture ethnicity among Australians (Stevens et al. 2015).

Following the initial inclusion, the ancestry question was removed from the census questionnaire in 1991 and 1996 (ABS 1994). The reason for removal as reported by the Australian Bureau of Statistics (ABS) was due to the costs involved in processing the data and the data underutilisation (1994). The data simply were not used enough to justify their collection. Moreover, the data were inconsistently reported, even by individuals within families and had the potential to change across time (Khoo 1991).

During the preparations for the 1996 Census, the ABS tested a more comprehensive approach to the collection of ancestry based on submissions received as part of the consultation process. Data users and experts (including government departments, community groups and academics) gave evidence for the need for the inclusion of a question that adequately captured ethnicity information (ABS 1994). The 
ABS tested two questions prior to the 1996 Census, with the different forms delivered to two alternate households in the pilot fieldwork. The trialled questions sought to consider whether ancestry differed to that of country of birth for respondents based on objective versus respondent self-identified information. 'Is the person's ancestry different from their country of birth?' was asked in a more yes/no objective framing versus 'Does the person identify with an ancestry different from their country of birth?'. Data from this trial (including follow up interviews) showed that ancestry was not reported where Australians did indeed have non-Australian heritage (ABS 1994). In other words, the ancestry question failed to elicit complete and accurate data.

In the 1994 report, the ABS (1994) stated that "the ancestry question could not replace any of the surrogate measures of ancestry which were used for service delivery, and one key issue under debate was whether the additional information from the ancestry question warranted the additional respondent load and resources needed to collect and process the question".

Citing concerns that the concept of ancestry was not appropriately and consistently understood by all, the ABS recommended no ancestry question be included the 1996 Census. Yet in 2001 the ancestry question (deemed to be inadequate and of little use previously) was again included, allowing only two responses of ancestry presumably for the maternal and paternal lines (ABS 2002). It appears Australia has merely sought to avoid the issue of ethnicity altogether, but this does not mean the issues concerning ethnic identity cease to exist (Perkins 2004).

Since its initial inclusion 35 years ago, little has changed in the way ancestry data is collected in the Australian census, with only minor reordering of the top potential responses. Such an approach does not enable the identification of ethnicity beyond one or two generations. The issues concerning adequacy and appropriateness of the ancestry question have not been addressed and remain today (Rocha et al. 2018).

There have been notable attempts to better reflect Australia's diversity in data, including work by Hopkins (2017) in the context of law enforcement. That said the ethnic classification system proposed for Victoria by Hopkins focuses on the physical attributes of race and ethnicity, and as such is not an appropriate means to collect self-identified ethnic identity via the census in Australia.

The justification and identified benefits considered for a more comprehensive and nuanced question or suite of questions concerning ancestry failed to account for the empowering of individuals and representative nature of collecting such data. Furthermore, Australia's increasing diversity through mixed partnering demands more contemporary data collection.

\subsection{International context}

Australia shares a similar demographic profile, and history of British colonisation and subsequent migration with a number of countries, including New Zealand (NZ) and Canada. Both the NZ and Canada censuses capture ethnic identity. Additionally, ethnicity is collected in the census conducted in the United Kingdom (UK). The censuses of NZ, Canada and the UK offer examples to help inform the formulation of contemporary collection of ethnic identity in Australia.

Ethnicity has been collected in New Zealand (NZ) censuses since 1926, albeit crudely and prior to the 1976 census based on outdated biological concepts of race and blood purity. A significant shift, 
however, occurred in the 1986 Census questionnaire when self-identified ethnicity was first asked (Cormack 2010). The initial 1986 ethnicity question resembles that asked on the 2018 NZ household form (see Table 1), where respondents are asked to indicate all the ethnic groups they belong to. A major flaw of the NZ ethnicity census question is that it does not reflect more recent, and diverse, migration flows (Statistics New Zealand 2001). A report by the NZ statistics agency found the narrow ethnic groupings failed to adequately reflect the contemporary population and indeed led to data inconsistencies over time.

Table 1: Ethnicity census question, New Zealand 2018 English form

\begin{tabular}{|l|}
\hline Question: Which ethnic groups do you belong to? Select all that apply to you. \\
\hline New Zealand European \\
\hline Maori \\
\hline Samoan \\
\hline Cook Islands Maori \\
\hline Tongan \\
\hline Niuean \\
\hline Chinese \\
\hline Indian \\
\hline Other, eg. Dutch, Japanese, Tokelauan \\
\hline
\end{tabular}

Source: Statistics New Zealand (2018)

The Office for National Statistics (ONS) has collected ethnicity in censuses undertaken in the United Kingdom (UK) since 1991 (Barton 2020). The collection of ethnicity in England comprises five main groups, each with further specified groupings (Table 2). Respondents choose one broad group and then select one of the more detailed groupings within. The English census form includes more detail than that of NZ, yet restricts the number of options individuals can identify with. Furthermore, the UK approach collapses or precodes options, which is not recommended by the United Nations on the collection of ethnicity data (United Nations 2017). Nevertheless, a strength of the UK collection of ethnicity in the census is the inclusion of the mixed or multiple ethnic group.

Ethnicity is collected in the Canadian census based on origins of respondents' ancestors, rather than self-identified affiliation. Since 1871, a question on ethnic and cultural origins has formed part of the Census of Population in Canada in some form or another (Statistics Canada 2020). In the 2021 Canadian census individuals are asked about the ethnic or cultural origins of this person's ancestors. A list of over 500 ethnic or cultural origins are included as a guide, based on commonly indicated groups. Any number of ethnic or cultural origins can be reported. The Canadian census question largely conforms with international recommendations for the collection of ethnicity data. 
Table 2: Ethnicity census question, England \& Wales 2021 household form

\begin{tabular}{|l|l|}
\hline $\begin{array}{l}\text { Question: What is your ethnic group? Choose one section from A to E, then tick one box to best } \\
\text { describe your ethnic group or background }\end{array}$ \\
\hline A White & - English, Welsh, Scottish, Northern Irish or British \\
& $\begin{array}{l}\text { - Irish } \\
\text { - Gypsy or Irish Traveller }\end{array}$ \\
\hline $\begin{array}{l}\text { B Mixed or Multiple ethnic } \\
\text { groups }\end{array}$ & - White and Black Caribbean \\
& - White and Black African \\
\hline C Asian or Asian British & - Anyite and Asian \\
& - Indian \\
& - Pakistani \\
\hline D Black, Black British, & - Bangladeshi \\
Caribbean or African & - Any other Asian background, write in \\
\hline E Other ethnic group & - Caribbean \\
& - African background, write in below \\
\hline
\end{tabular}

Source: Office for National Statistics (2020)

Table 3: Census question on ethnic or cultural origins, Canada 2021

\begin{tabular}{l} 
Question: What were the ethnic or cultural origins of this person's ancestors? \\
\hline Ancestors may have Indigenous origins, or origins that refer to different countries, or other \\
origins that may not refer to different countries. \\
For examples, refer to this list of ethnic or cultural origins. \\
Specify as many origins as applicable.
\end{tabular}

Source: Statistics Canada (2020)

\section{Proposed census question}

Development of a census question seeking data on ethnicity must recognise the potential for, and concerns relating to, racial profiling and use of the data to cause harm. There is a persistent fear, particularly among marginalised groups, that census data might be used to identify and discriminate against minority and vulnerable groups (Price 2016). The identification and maltreatment of Jewish people in Nazi Germany (Luebke \& Milton 1994) or internment of Japanese people in the United States (Anderson \& Seltzer 2007) are often examples used to illustrate harms.

While no guarantees can be made to ensure ethnicity data (or census data more broadly) is not misused in the interpretation and use by the public, the proposed census additions do not make people more vulnerable to discrimination than the current census questions. The legislative safeguards of the Census and Statistics Act 1905 and the Privacy Act 1988 are two measures which go some way to mitigate potential misuse of census data by setting out the limited uses of unit record data (ABS 2021). 
The risk of oversimplification of census items relating to ethnicity, on the other hand, should also be avoided to prevent any potential for promoting social fractures or othering of people. For example, collapsing data potential by precoding and lumping options together can lead to minimising identity (United Nations 2017). It is thus vital that any ethnicity question for census be formulated with expert (including advice from advocacy groups) and user input to ensure appropriateness. Testing of such a question is fundamental to ensure robust data while balancing the ethical implications of collecting ethnic identity information.

Ethnicity in contemporary Australia could be understood by employing a question in census similar to the framing of that used in the NZ census with the response options like that used by Statistics Canada. Such an approach would draw on a familiarity among respondents with the way in which ancestry has been previously collected in Australia, minimising reactivity and misunderstanding. Table 4 presents a potential solution to overcome the problems identified in the collection of ancestry and surrogate ethnicity data in the census. The proposed question seeks to collect ethnic identity by asking which ethnic groups people belong to or identify with. Rather than constraining the selection of groups, it is advised that all options should be selected by respondents as they apply (United Nations 2017). In the initial application of this proposed question, the options could be listed as is the case in the Canadian census. The list of options could be informed by the Australian standard classification for cultural and ethnic groups (ABS 2019). Analysis of the data could then be used to refine the list of ethnic origins. Clear instructions on how to complete the proposed census question on ethnic identity, especially for those of multiracial backgrounds and identity, should be developed in collaboration with a range of stakeholders (including experts, interest groups, and data users).

Table 4: Proposed census question on ethnic identity, Australia 2026 Census

Question: Which ethnic groups do you belong to/identify with? Select all that apply to you. For examples, refer to this list of ethnic or cultural origins.

Specify as many origins as applicable.

This proposed question does not seek to replace any questions relating to First Nations status; any ethnicity question complements such information. There are likely interconnections between an ethnicity question and that of determining Indigeneity, but as the current census questionnaire attests these questions can coexist on the national enumeration form. Changes to ethnic identity information collected in the census is best informed by stakeholders comprised of First Nations elders.

\section{Discussion}

Collection of ethnicity or ethnic identity data has posed great challenges for considerable time in Australia, despite the immense importance of such information. The collection of surrogate and direct measures of ethnicity in the national census has proven inadequate for completeness and contemporary applications. Whether the collection of ethnic identity data is stuck in outdated notions of race and identity, being held captive to political arguments or government administration, 
it is beyond time the national census keep step with the needs and wants to truly reflect Australian diversity in the national snap shot.

Lack of experience responding to a new question format to capture ethnicity should not be used to avoid innovation. Nor should the status quo be maintained in the ancestry question because it is simply too difficult to try something else - it appears this has been the case since 2001, despite the evidence to the contrary and poor-quality data. Australians are now more than ever aware of the importance of better understanding the diversity of the nation. And there is sufficient opportunity to test and prepare people via a public campaign (from the ABS in collaboration with community groups and organisations) to ensure accurate and complete data.

Ultimately, a more comprehensive and appropriate question for the contemporary collection of ethnicity or ethnic identity is a priority for the Australian census in 2026, especially if it the nation's last traditional census undertaking.

\section{References}

Allen L (2020) The Future of Us: Demography Gets a Makeover. Sydney: NewSouth Publishing.

Anderson M and W Seltzer (2007) Challenges to the confidentiality of US federal statistics, 1910-1965. Journal of Official Statistics 23(1): 1-34.

ABS (1984) The Measurement of Ethnicity in the Australian Census of Population and Housing. Report to the Australian Statistician by the 1986 Population Census Ethnicity Committee. Australian Bureau of Statistics, Canberra.

ABS (1994) Census Working Paper 94/4 - Ancestry, 1996. https://www.abs.gov.au/ausstats/abs@.nsf/7d12b0f6763c78caca257061001cc588/a6845d677bc 8c50fca2570610032c06d!OpenDocument. Accessed on 10 February 2021.

ABS (2002) 2001 Census of Population and Housing - Fact Sheet: Ancestry, 2001. https://www.abs.gov.au/AUSSTATS/abs@.nsf/Lookup/2970.0.55.006Main+Features12001?Open Document. Accessed on 11 February 2021.

ABS (2019) Australian Standard Classification of Cultural and Ethnic Groups (ASCCEG), 2019. https://www.abs.gov.au/ausstats/abs@.nsf/7d12b0f6763c78caca257061001cc588/8e81298ff9bf d160ca257ff1001e661e!OpenDocument Accessed on 30 April 2021.

ABS (2020) 2021 Census topics and data release plan. https://www.abs.gov.au/statistics/research/2021census-topics-and-data-release-plan\#data-download. Accessed on 10 February 2021.

ABS (2021) 2021 Census Privacy Statement. https://www.abs.gov.au/census/planning-2021census/privacy. Accessed on 30 April 2021.

Barton C (2020) Preparing for the 2021 Census (England and Wales). House of Commons Library Briefing Paper, Number 8531. 22 October. https://commonslibrary.parliament.uk/research-briefings/cbp8531/ Accessed on 19 May 2021.

Cormack D (2010) The practice and politics of counting: ethnicity data in official statistics in Aotearoa/New Zealand. Wellington: Te Rōpū Rangahau Hauora a Eru Pōmare. https://www.otago.ac.nz/wellington/otago600095.pdf. Accessed on 10 February 2021.

Federation of Ethnic Communities' Council of Australia (2020) If We Don't Count It...It Doesn't Count: Towards a Consistent National Data Collection and Reporting on Cultural, Ethnic and Linguistic Diversity. https://fecca.org.au/wp-content/uploads/2020/10/CALD-DATA-ISSUES-PAPERFINAL2.pdf. Accessed on 11 February 2021. 
Green E, Sarrasin O and N Fasel (2015) Immigration: social psychology aspects. In: Wright J D (ed) International Encyclopedia of the Social \& Behavioural Sciences, 2nd edition, volume 11. London: Elsevier.

Hopkins T (2017) Monitoring Racial Profiling: Introducing a Scheme to Prevent Unlawful Stops and Searches by Victoria Police. https://www.policeaccountability.org.au/wpcontent/uploads/2017/08/monitoringRP report softcopy FINAL 22082017.pdf. Accessed on 11 February 2021.

Horn R (1987) Ethnic origin in the Australian census. Journal of the Australian Population Association 4(1): 1-12. https://doi.org/10.1007/BF03029575

Horn R (1993) The validity of Australian Ancestry Statistics. Journal of the Australian Population Association 10(2): 119-126. https://doi.org/10.1007/BF03029418

Jupp J (2001) The Australian People: An Encyclopedia of the Nation, Its People and Their Origins. Cambridge: Cambridge University Press.

Khoo S-E (1991) Consistency of ancestry reporting between parents and children in the 1986 census. Journal of the Australian Population Association 8(2): 129-139. https://doi.org/10.1007/BF03029441

Luebke D and S Milton (1994) Locating the victim: an overview of census-taking, tabulation technology, and persecution in Nazi Germany. Annals of the History of Computing 16(3): 25-39. https://doi.org/10.1109/MAHC.1994.298418

Office of National Statistics (2020) Census 2021 Paper Questionnaires. https://www.ons.gov.uk/census/censustransformationprogramme/questiondevelopment/census 2021 paperquestionnaires. Accessed on 11 February 2021.

Perkins M (2004) Australian mixed race. European Journal of Cultural Studies 7(2): 177-199. https://doi.org/10.1177/1367549404042493

Price J (2016) Trying to sense of the census, but I'm still not convinced on privacy. The Sydney Morning Herald, 9 August. https://www.smh.com.au/opinion/trying-to-make-sense-of-the-census-but-imstill-not-convinced-on-privacy-20160808-gqnj9q.html. Accessed on 30 April 2021.

Rocha L, Fozdar F, Acedera K and B Yeoh (2018) Mixing race, nation, and ethnicity in Asia and Australasia. Social Identities 25(3): 289-293. https://doi.org/10.1080/13504630.2018.1500162

Statistics Canada (2020) Ethnic or cultural origins: Technical report on changes for the 2021 Census https://www12.statcan.gc.ca/census-recensement/2021/ref/98-20-0002/982000022020001eng.cfm\#a7. Accessed on 11 February 2021.

Statistics New Zealand (2001) Review of the measurement of ethnicity: Classifications and issues. https://www.stats.govt.nz/methods/review-of-the-measurement-of-ethnicity-classifications-andissues. Accessed on 30 April 2021.

Statistics New Zealand (2018) 2018 Census: Design of forms https://www.stats.govt.nz/assets/Reports/2018-census-design-of-forms/2018-Census-Design-offorms.pdf. Accessed on 11 February 2021.

Stevens G, Ishizawa H and D Grbic (2015) Measuring race and ethnicity in the censuses of Australia, Canada, and the United States: Parallels and paradoxes. Canadian Studies in Population 42(1-2): 13-34. https://doi.org/10.25336/P6PW39

United Nations (2017) Principles and Recommendations for Population and Housing Censuses Revision 3. New York: Department of Economic and Social Affairs Statistics Division. 